\title{
Bacteriological Profile and Antibiogram of isolates from Bloodstream Infections in Patients Admitted in ICU from a Tertiary care hospital, Nerul, Navi Mumbai, India
}

\author{
Jyoti P. Sonawane ${ }^{1}$, Keertana S. Shetty ${ }^{2}$, N. Kamath ${ }^{2 *}$, \\ NitinBharos ${ }^{3}$ and Abhay S. Chowdhary ${ }^{4}$ \\ ${ }^{1}$ Department of Microbiology, Dr.D.Y.Patil Medical College and Hospital, \\ Nerul, Navi Mumbai, India \\ ${ }^{2}$ Department of Microbiology, GMC, Silvassa, India \\ *Corresponding author
}

\section{A B S T R A C T}

\section{Keywords}

Bloodstream infections (BSI), Intensive care unit (ICU), Multi drug resistant (MDR), Blood cultures, and Antimicrobial sensitivity.

\section{Article Info}

Accepted:

18 August 2019 Available Online: 10 September 2019
Bloodstream infections are frequent and life - threatening, can lead to increase in morbidity, mortality and health care cost of patients admitted in intensive care unit (ICU). In addition to this, infections due to emerging multidrug resistant (MDR) microorganisms, the treatment becomes challenging. With the rising problem of drug resistance, the present study was undertaken to evaluate the most prevalent bacterial pathogen causing Bloodstream infections in adult patients admitted to an Intensive Care Unit (ICU) with their antimicrobial sensitivity pattern. A retrospective analysis of data was done on the blood cultures received from 817 patients with clinically suspected bloodstream infections, admitted in Medical ICU of tertiary care hospital, Navi Mumbai, between October 2016 and October 2018. All the samples were received and processed in the Department of Microbiology, using standard microbiological techniques and antimicrobial sensitivity was done according to CLSI guidelines. From 817 patients, the positive growth for pathogen was observed in $165(20.19 \%)$ patients. 167 isolates were identified, maximum isolates were Gram - negative 120 (71.86\%), Gram - positive were 31 (18.56\%) and Candida spp. were 16 (9.58\%). Among bacterial isolates, there was a predominance of Klebsiella pneumoniae 37 (22.15\%) followed by Acinetobacter spp. 31 (18.56\%), Escherichia coli 29 (17.36\%), Pseudomonas aeruginosa 16 (9.58\%) \&Enterococcus spp. 14 (8.38\%). Gram - negative bacterial pathogens showed decreasing sensitivity to Imipenem, Piperacillin - tazobactum, Aminoglycosides, Third - generation Cephalosporins\& Cephalosporin. Whereas all gram - positive bacterial isolates were sensitive to Vancomycin and Linezolid while resistant to Penicillin. This study showed the high prevalence of multi drug resistant gram - negative pathogens causing bloodstream infections in our ICU setting. Thus a continues surveillance of prevalent etiological pathogens of BSI along with their antibiotic susceptibility pattern will be helpful to the clinicians in choosing the proper antimicrobials. And clinical management of BSI will minimize the emergence of multi drug resistance.

\section{Introduction}

Bloodstream infections, frequent and life threatening, lead to increase in mortality and morbidity among critically ill patients admitted in ICU ${ }^{(1)}$. Critically ill patients are particularly predisposed to the acquisition of BSIs, which occur in approximately $7 \%$ of all patients within the first month of hospitalization in Intensive care units (ICUs). The acquisition of a Bloodstream infection also results in increased length of ICU stay 
and Healthcare related cost ${ }^{(2,3)}$. Approximately 200,000 cases of bacteraemia and fungemia occur annually with mortality rates ranging from $20-50 \%^{(4,5)}$.

The intensive care unit (ICU) often is called the epicentre of infections, due to its extremely vulnerable population (reduced host defences deregulating the immune responses) and increased risk of becoming infected through multiple procedures and use of invasive devices (intubation, mechanical ventilation, vascular access, etc.). In addition, several drugs may be administered, which also predispose for infections, such as pneumonia, e.g., by reducing the cough and swallow reflexes (sedatives, muscle relaxants) or by distorting the normal non-pathogenic bacterial flora (e.g., stress ulcer prophylaxis (6, ${ }^{7)}$.Consequently, the ICU population has one of the highest occurrence rates of (nosocomial) infections (20-30\% of all ICUadmissions) $(8,9)$, leading to an enormous impact on morbidity, hospital costs, and often, survival $^{(10-12)}$.

Pattern of organisms causing infections and their antibiotic resistance pattern vary widely from one country to another, as well as one hospital to other and even among ICUs within one hospital ${ }^{(13)}$.

Among gram negative bacteria, Acinetobacter spp., Pseudomonas aeruginosa, E.coli, Klebsiella, H. influenza, Neisseria meningitides are responsible for BSI along with CONS, S.aureus, Enterococci and alpha haemolytic Streptococci among gram positive

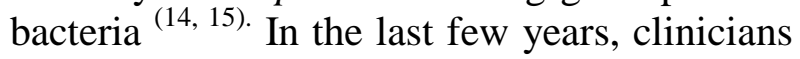
have witnessed a growing incidence of BSIs by bacteria with resistance against commonly used antimicrobials.

During the past decades, a shift in the MDR dilemma has been noted from gram-positive to gram-negative bacteria, especially due to the scarceness of new antimicrobial agents active against resistant gram-negative microorganisms ${ }^{(16)}$.

Among gram-positive organisms, the most important resistant microorganisms in the ICU are currently methicillin-(oxacillin resistant Staphylococcus aureus, and vancomycin-resistant enterococci (6, 16, and 17). In gram-negative bacteria, the resistance is mainly due to the rapid increase of extendedspectrum Beta-lactamases (ESBLs) in Klebsiellapneumoniae, Escherichia coli, and Proteus mirabilis; high level thirdgeneration cephalosporin Beta-lactamase resistance among Enterobacter spp. and Citrobacter spp., and MDR in Pseudomonas aeruginosa, Acinetobacter spp., and Stenotrophomonasmaltophilia ${ }^{(6,17)}$.

This rising problem of emerging drug resistance among bloodstream pathogens limits the therapeutic options and complicate patient's management.

With this background, the present study was undertaken to identify the most prevalent bacteria isolated from patients suspected with Blood stream infections along with antibiotic sensitivity pattern of isolates thus providing useful guidance to clinicians to modify antibiotic therapy thus minimizing morbidity, mortality and emergence of resistant organisms.

\section{Materials and Methods}

The study was carried out in the Department of Microbiology of Dr. D.Y. Patil Medical College and Hospital, Nerul, Navi Mumbai wherein the retrospective analysis of blood cultures received during two years period from October 2016 to October 2018, was done.

A total of 817 blood samples for culture were received from clinically suspected adult 
patients with bloodstream infections who were admitted in MICU.

\section{Inclusion criteria}

Patients who had a blood cultures that grew aerobic bacterial isolate from two sets of blood cultures taken at different intervals of time with their antibiogram during their stay in Medical ICU were eligible for the study.

\section{Exclusion criteria}

Negative blood cultures, fungal isolates and contaminant growths were excluded from the study.

\section{Sample Collection}

Blood specimens were obtained according to the standard sample collection protocol followed in hospital by a trained phlebotomist.

\section{Sample processing}

Blood for culture samples collected from clinically suspected bacteraemia cases under strict aseptic precautions. The venepuncture site was disinfected with $70 \%$ alcohol and $2 \%$

Tincture of iodine, before drawing blood. A volume of $10 \mathrm{ml}$ of blood from adult patient was collected and inoculated into Adult BACTEC blood culture bottles and incubated in an automated BACTEC 9050 blood culture instrument (Becton - Dickenson, USA) at $37^{0} \mathrm{C}$.

All Bactec positive samples were subjected to inoculation on 5\% Sheep Blood Agar, Chocolate Agar and MacConkey'sAgar, followed byGram staining and the plates were incubated at $37^{\circ} \mathrm{C}$ for 24 hours and plates were observed for growth. The growth was identified by colonial characteristics(phenotypic identification),
Gram's stain and standard biochemical tests $(18,19)$

Antibiotic susceptibility testing was done for the pathogenic isolates on Mueller - Hinton agar by Kirby-Bauer disc diffusion method and interpreted according to CLSI guidelines (20)

Control strains of Escherichia coli ATCC 25922, Pseudomonas aeruginosa 27853 and Staphylococcus aureus ATCC 25923 were used.

\section{Statistical Analysis}

Data was entered in MS-Excel worksheet for calculation purposes. Further data was analysed using Statistical software IBM SPSS Statistics version 21.0 and results were presented using frequency and percentages. The results were summarised using graphical and tabular presentation. The chi-square test was used to assess the association between variables. Also z-test for two proportions was used to compare the proportions. A p-value of less than 0.05 was considered as statistical significant.

\section{Results and Discussion}

During the study period from October 2016 to October 2018, a total of 817 blood samples from patients suspected of blood stream infections were received and analysed. Positive growth of pathogen was observed in $163(19.95 \%)$ blood samples.

Negative growth was seen in $640(78.34 \%)$ blood samples whereas from $14(1.71 \%)$ blood samples, the contaminants were recovered.

Most of the culture positive samples were of monomicrobial aetiology (97.55\%) and from four samples $(2.45 \%)$ more than one organism were isolated. 
Among 163 patients, 109 (66.87\%) were males and 54 (33.13\%) were females.

The maximum bloodstream infections were observed in above 60 years of age group. The chi-square analysis indicates bloodstream infection was maximum in higher age groups $(\mathrm{p}<.01)$.

From 163 patients, 167 isolates were recovered. Out of 167 isolates, 120 (71.86\%) were Gram-negative, 31 (18.56\%) were Gram-positive and 16 (9.58\%) were Candida spp

Among Gram-negative isolates, predominant pathogen was Klebsiella pneumoneae 37 (22.15\%) followed by Acinetobacter spp. 31 (18.56\%), E.coli $29 \quad(17.36 \%)$ and Pseudomonas aerugenosa $16 \quad(9.58 \%)$ (p $<.01)$. Whereas among Gram-positive isolates, maximum isolation was of Enterococcus spp. $14(8.38 \%)$ and Staphylococcus aureus $11(6.59 \%)(\mathrm{p}<.01)$.

Antimicobial sensitivity patterns for Gram positive isolates and Gram - negative isolates were interpreted according to CLSI guidelines and are represented in TABLE 3 and TABLE 4 respectively. All gram-positive isolates showed $100 \%$ sensitivity towards Vancomycin and Linezolid $(\mathrm{p}<.001)$. More than 90\% enterococcal isolates were resistant to Gentamicin, Ciprofloxacin, Penicillin and
Erythromycin $(\mathrm{p}<.01)$. Among S.aureus, Methicillin resistance (MRSA) was observed in $54.55 \%$ of the isolates and $100 \%$ were resistant to Penicillin, Erythromycin whereas low level resistance was shown to Ciprofloxacin \& Gentamicin $(\mathrm{p}<.01)$.

$75 \%$ strains of Coagulase - negative Staphylococcal spp. (CONS) were Methicillin resistant and $100 \%$ resistance to Penicillin, Erythromycin, Ciprofloxacin and Gentamicin $(\mathrm{p}<.01)$.

2 Streptococcal spp. showed $100 \%$ sensitivity to all antibiotics.

Among Gram-negative isolates, maximum isolataion was of Klesiella pneumoniae and Acinetobacter $\operatorname{spp}(\mathrm{p}<.01)$

Among Gram - negative isolates, Klebsiella pneumoniae, Pseudomonas aeruginosa and Acinetobacter spp. showed decresing sensitivity to Imipenem, Piperacillin + Tazobactum, Aminoglycosides, Ciprofloxacin, third - generation cephalosporins. $(\mathrm{p}<.01)$.

35/37 (94.59\%) of Klebsiella spp. were resistant to Extended spectrum $\beta$ - lactamases while 28/37 (75.68\%) and 21/37(56.76\%) resistant to Piperacillin - Tazobactum and Imipenem respectively. $(\mathrm{p}<.01)$.

Table.1 Demographic characteristics of the patients

\begin{tabular}{|l|l|l|l|}
\hline AGE (years) & MALES & FEMALES & TOTAL \\
\hline $\mathbf{1 3}-\mathbf{2 0}$ & 01 & 01 & 02 \\
\hline $\mathbf{2 1}-\mathbf{4 0}$ & 25 & 11 & 36 \\
\hline $\mathbf{4 1}-\mathbf{6 0}$ & 39 & 19 & 58 \\
\hline Above 60 & 44 & 23 & 67 \\
\hline TOTAL & $\mathbf{1 0 9}$ & $\mathbf{5 4}$ & $\mathbf{1 6 3}$ \\
\hline
\end{tabular}

$(\mathrm{n}=163)$.

The number of males were significantly higher than females $(\mathrm{p}<.01)$.

Male to Female ratio was approximately 2: 1. 
Table.2 Distribution of bacterial isolates from positive blood cultures

$$
(\mathrm{n}=167)
$$

\begin{tabular}{|l|c|}
\hline Causative pathogens & NUMBER (\%) \\
\hline Klebsiella pneumoniae & $37(22.15 \%)$ \\
\hline Acinetobacter spp. & $31(18.56 \%)$ \\
\hline E.coli & $29(17.36 \%)$ \\
\hline Pseudomonas aeruginosa & $16(9.58 \%)$ \\
\hline Enterobacter spp. & $02(1.20 \%)$ \\
\hline Proteus spp. & $02(1.20 \%)$ \\
\hline Salmonella typhi & $02(1.20 \%)$ \\
\hline Citrobacter spp. & $01(0.60 \%)$ \\
\hline Enterococcus spp. & $14(8.38 \%)$ \\
\hline S.aureus & $11(6.59 \%)$ \\
\hline CONS & $04(2.40 \%)$ \\
\hline Streptococcus spp. & $02(1.20 \%)$ \\
\hline Candida spp. & $16(9.58 \%)$ \\
\hline TOTAL & $\mathbf{1 6 7}(\mathbf{1 0 0 \%})$ \\
\hline
\end{tabular}

Table. 3 Antimicrobial Susceptibility pattern in Gram-positive isolates

\begin{tabular}{|c|c|c|c|c|c|c|c|c|}
\hline \multirow[t]{2}{*}{ ANTIBIOTICS } & \multicolumn{2}{|c|}{$\begin{array}{c}\text { S.aureus } \\
(\mathrm{n}=11)\end{array}$} & \multicolumn{2}{|c|}{$\begin{array}{c}\text { CONS } \\
(n=4)\end{array}$} & \multicolumn{2}{|c|}{$\begin{array}{c}\text { Enterococcus spp. } \\
\quad(n=14)\end{array}$} & \multicolumn{2}{|c|}{$\begin{array}{l}\text { Streptococcus } \\
\operatorname{spp} .(n=2)\end{array}$} \\
\hline & $S(\%)$ & $\mathbf{R}(\%)$ & S (\%) & $\mathbf{R}(\%)$ & $\mathbf{S}(\%)$ & $\mathbf{R}(\%)$ & S (\%) & $\mathbf{R}(\%)$ \\
\hline $\begin{array}{l}\text { Penicillin } \\
\text { (10 units ) }\end{array}$ & 00 & $100 \%$ & 00 & $100 \%$ & $1(7.69 \%)$ & $13(92.86 \%)$ & 100 & 00 \\
\hline $\begin{array}{l}\text { Erythromycin } \\
\text { (15mcg) }\end{array}$ & 00 & $100 \%$ & 00 & $100 \%$ & 00 & $14(100 \%)$ & 100 & 00 \\
\hline $\begin{array}{l}\text { Cefoxitin } \\
\text { (30mcg) }\end{array}$ & $5(45.45 \%)$ & $6(54.55 \%)$ & $1(25 \%)$ & $3(75 \%)$ & - & - & - & - \\
\hline $\begin{array}{l}\text { Gentamicin } \\
\text { (10meg) }\end{array}$ & $3(27.27 \%)$ & $8(72.73 \%)$ & $1(25 \%)$ & $3(75 \%)$ & $1(7.69 \%)$ & $13(92.86 \%)$ & 100 & 00 \\
\hline $\begin{array}{l}\text { Vancomycin } \\
\text { (30mcg) }\end{array}$ & $11(100 \%)$ & $00(00 \%)$ & $4(100 \%)$ & 00 & $14(100 \%)$ & 00 & 100 & 00 \\
\hline $\begin{array}{l}\text { Linezolid } \\
\text { (30mcg) }\end{array}$ & $11(100 \%)$ & $00(00 \%)$ & $4(100 \%)$ & 00 & $14(100 \%)$ & 00 & 100 & 00 \\
\hline $\begin{array}{l}\text { Cotrimoxazole } \\
(1.25 / 23.75 \\
\text { mcg) }\end{array}$ & $2(18.18 \%)$ & $\begin{array}{l}9(81.82 \\
\%)\end{array}$ & 00 & $100 \%$ & - & - & 100 & 00 \\
\hline $\begin{array}{l}\text { Ciprofloxacin } \\
\text { (30meg) }\end{array}$ & $3(27.27 \%)$ & $\begin{array}{l}8(72.73 \\
\%)\end{array}$ & 00 & $100 \%$ & $1(7.69 \%)$ & $13(92.86 \%)$ & 100 & 00 \\
\hline
\end{tabular}


Table.4 Antimicrobial susceptibility of Gram-negative isolates

\begin{tabular}{|c|c|c|c|c|c|c|c|c|}
\hline Antibiotics & $\begin{array}{l}\text { Kleb.spp } \\
(\mathrm{n}=37)\end{array}$ & $\begin{array}{l}\text { E.coli } \\
(\mathbf{n}-29)\end{array}$ & $\begin{array}{l}\text { Enterobac } \\
\text { ter spp. } \\
(\mathrm{n}=2)\end{array}$ & $\begin{array}{l}\text { Citrobacter } \\
\text { spp. }(n=1)\end{array}$ & $\begin{array}{l}\text { Proteus } \\
\text { spp. } \\
(\mathrm{n}=2)\end{array}$ & $\begin{array}{l}\text { Acinetobac } \\
\text { ter spp. } \\
\quad(\mathrm{n}=31)\end{array}$ & $\begin{array}{l}\text { Pseudomonas } \\
\text { aeruginosa } \\
\text { (n-16) }\end{array}$ & $\begin{array}{l}\text { S.typhi } \\
(\mathrm{n}=2)\end{array}$ \\
\hline Amikacin & $15(40.54 \%)$ & $19(65.52 \%)$ & 00 & 00 & $1(50 \%)$ & $8(25.81 \%)$ & $7(43.75 \%)$ & $1(50 \%)$ \\
\hline Gentamicin & $15(40.54 \%)$ & $14(48.26 \%)$ & 00 & 00 & $1(50 \%)$ & $7(22.58 \%)$ & 00 & $1(50 \%)$ \\
\hline Ciprofloxacin & $11(29.73 \%)$ & $4(13.79 \%)$ & 00 & $1(100 \%)$ & 00 & $9(29.03 \%)$ & $10(62.5 \%)$ & $2(100 \%)$ \\
\hline Co-tromoxazole & $9(24.32 \%)$ & $6(20.69 \%)$ & 00 & $1(100 \%)$ & 00 & $9(29.03 \%)$ & 00 & $1(50 \%)$ \\
\hline Ampicillin & - & - & - & - & - & - & - & $2(! 00 \%)$ \\
\hline $\begin{array}{l}\text { Piperacillin+ } \\
\text { Tazobactum }\end{array}$ & $10(27.03 \%)$ & $15(51.72 \%)$ & 00 & 00 & $\begin{array}{l}2 \\
(100 \%)\end{array}$ & $9(29.03 \%)$ & $10(62.5 \%)$ & $1(50 \%)$ \\
\hline Imipenem & $16(43.24 \%)$ & $16(55.17 \%)$ & $1(50 \%)$ & 00 & $\begin{array}{l}2 \\
(100 \%)\end{array}$ & $\begin{array}{l}15 \\
(48.39 \%)\end{array}$ & $9(56.25 \%)$ & $\begin{array}{l}2 \\
(100 \%)\end{array}$ \\
\hline $\begin{array}{l}\text { Ceftazidime- } \\
\text { clavulanic acid }\end{array}$ & $2(5.41 \%)$ & $3(10.34 \%)$ & 00 & 00 & $1(50 \%)$ & $2(6.45 \%)$ & - & $2(100 \%)$ \\
\hline Ceftazidime & $2(5.41 \%)$ & $3(10.34 \%)$ & 00 & 00 & $1(50 \%)$ & $2(6.45 \%)$ & $4(25 \%)$ & $2(100 \%)$ \\
\hline Ceftriaxone & $2(5.41 \%)$ & $3(10.34 \%)$ & 00 & 00 & $1(50 \%)$ & $2(6.45 \%)$ & - & $\begin{array}{l}2 \\
(100 \%)\end{array}$ \\
\hline Cefotaxime & $2(5.41 \%)$ & $3(10.34 \%)$ & 00 & 00 & $1(50 \%)$ & $2(6.45 \%)$ & - & $\begin{array}{l}2 \\
(100 \%)\end{array}$ \\
\hline Tobramycin & - & - & - & - & - & - & $7(43.75 \%)$ & - \\
\hline Aztreonam & - & - & - & - & - & - & $1(6.25 \%)$ & - \\
\hline Cefepime & - & - & - & - & - & - & $5(31.25 \%)$ & - \\
\hline
\end{tabular}

Fig.1 Demographic Characteristics of the Patients $(n=163)$.

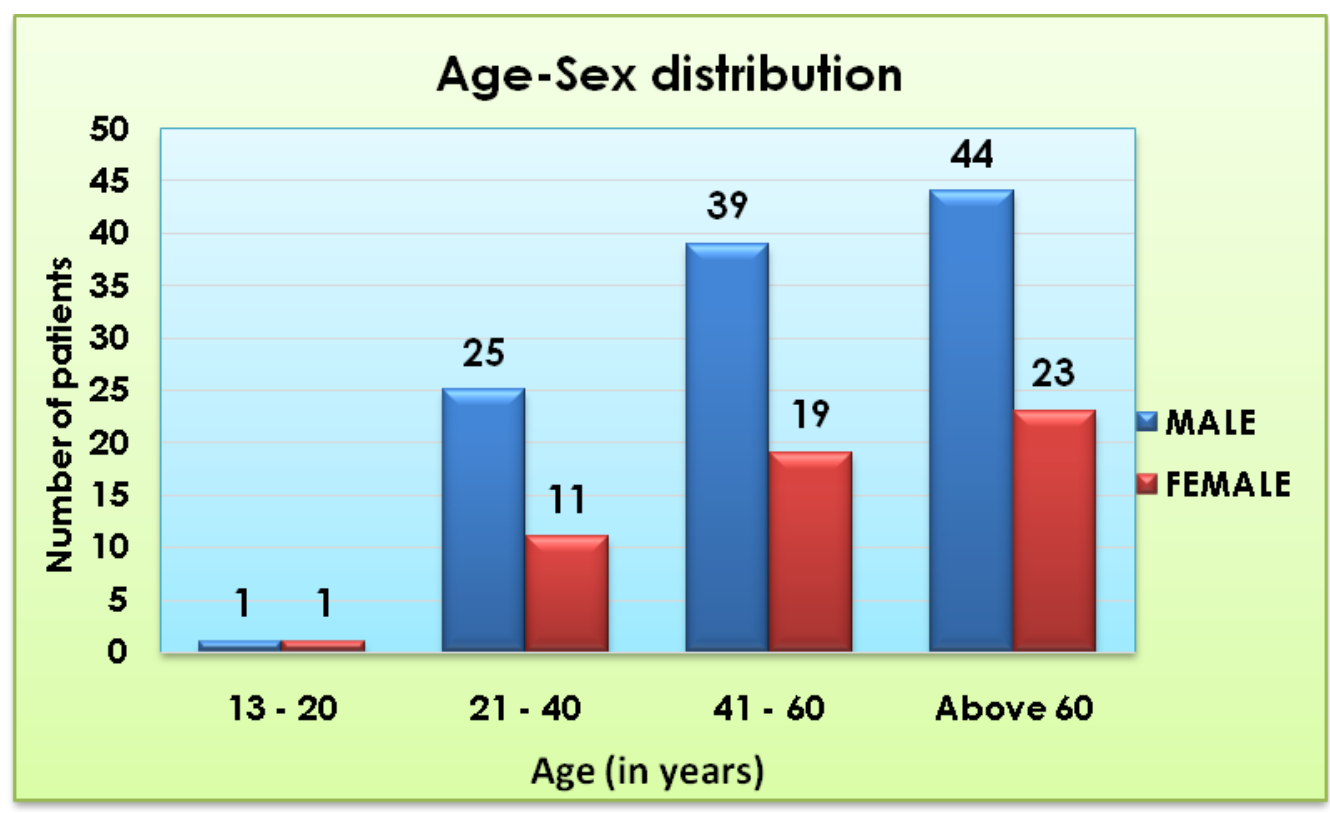


Fig.2 Percentage of isolates $(n=167)$

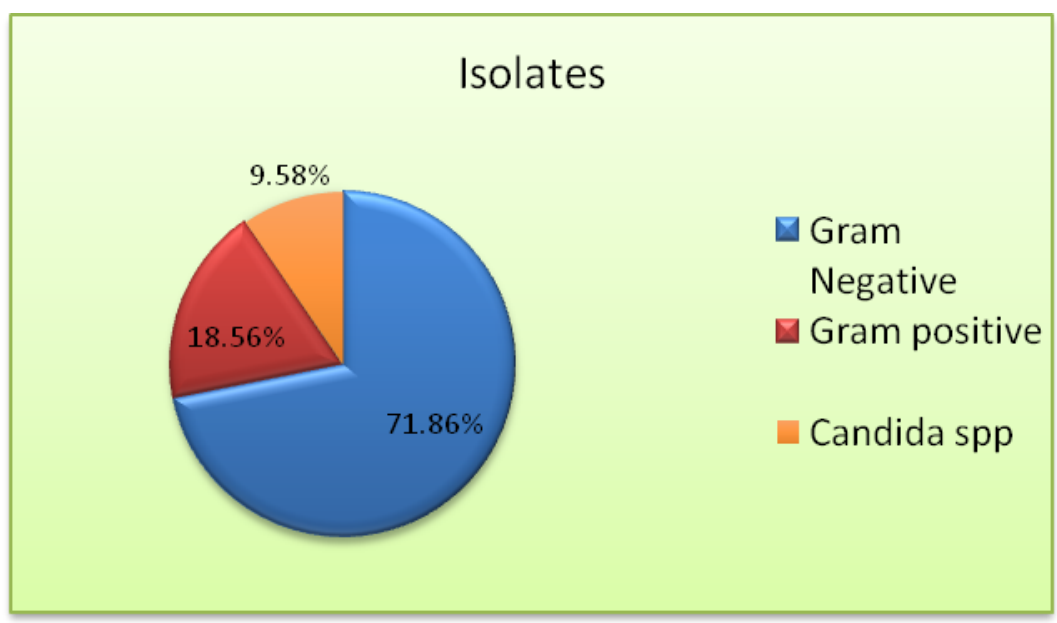

Fig.3 Antimicrobial Susceptibility Pattern of Gram - positive isolates

$$
(\mathrm{n}=31)
$$

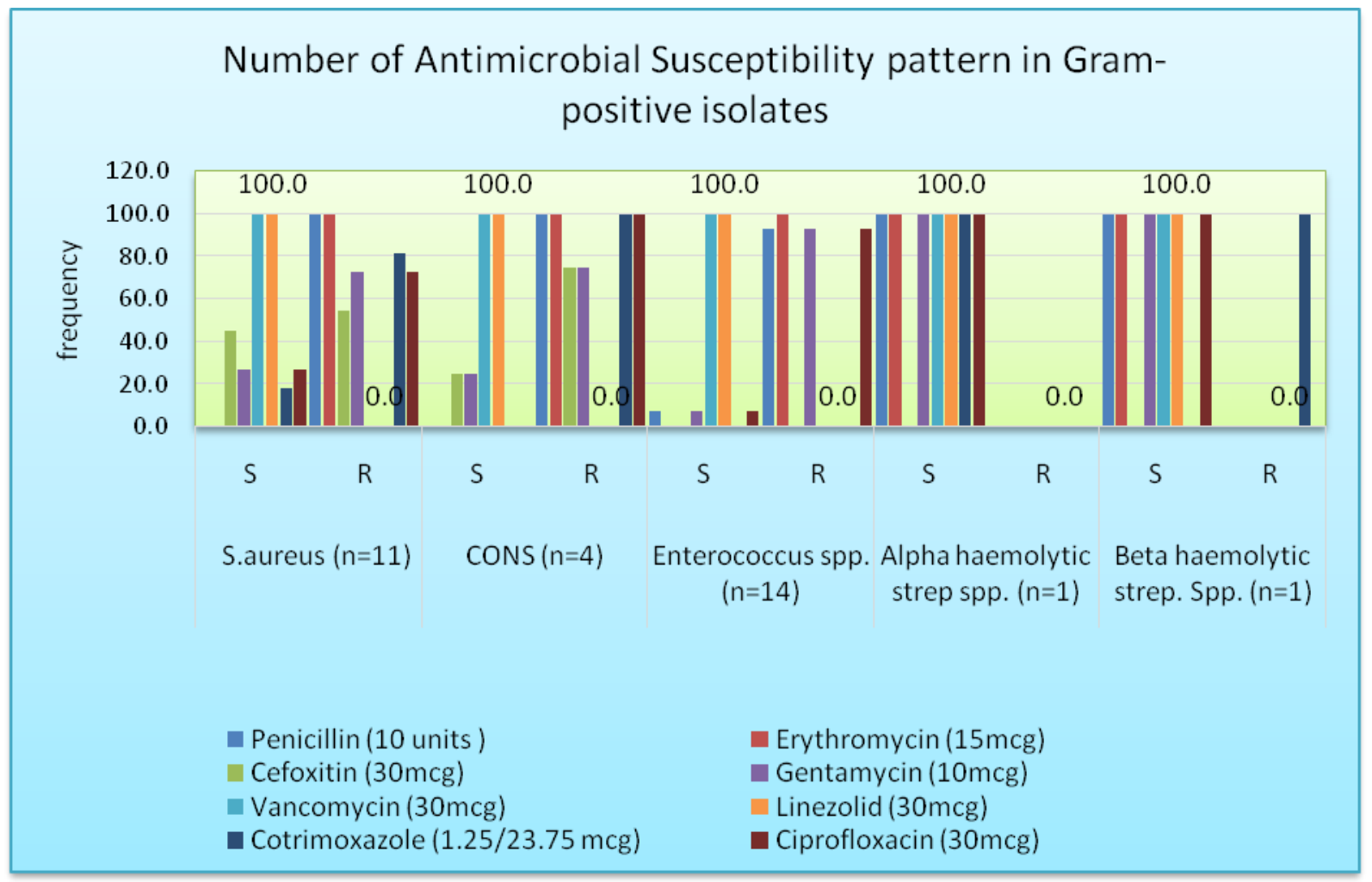


Fig.4 \% of antimicrobial susceptibility of Gram - negative isolates

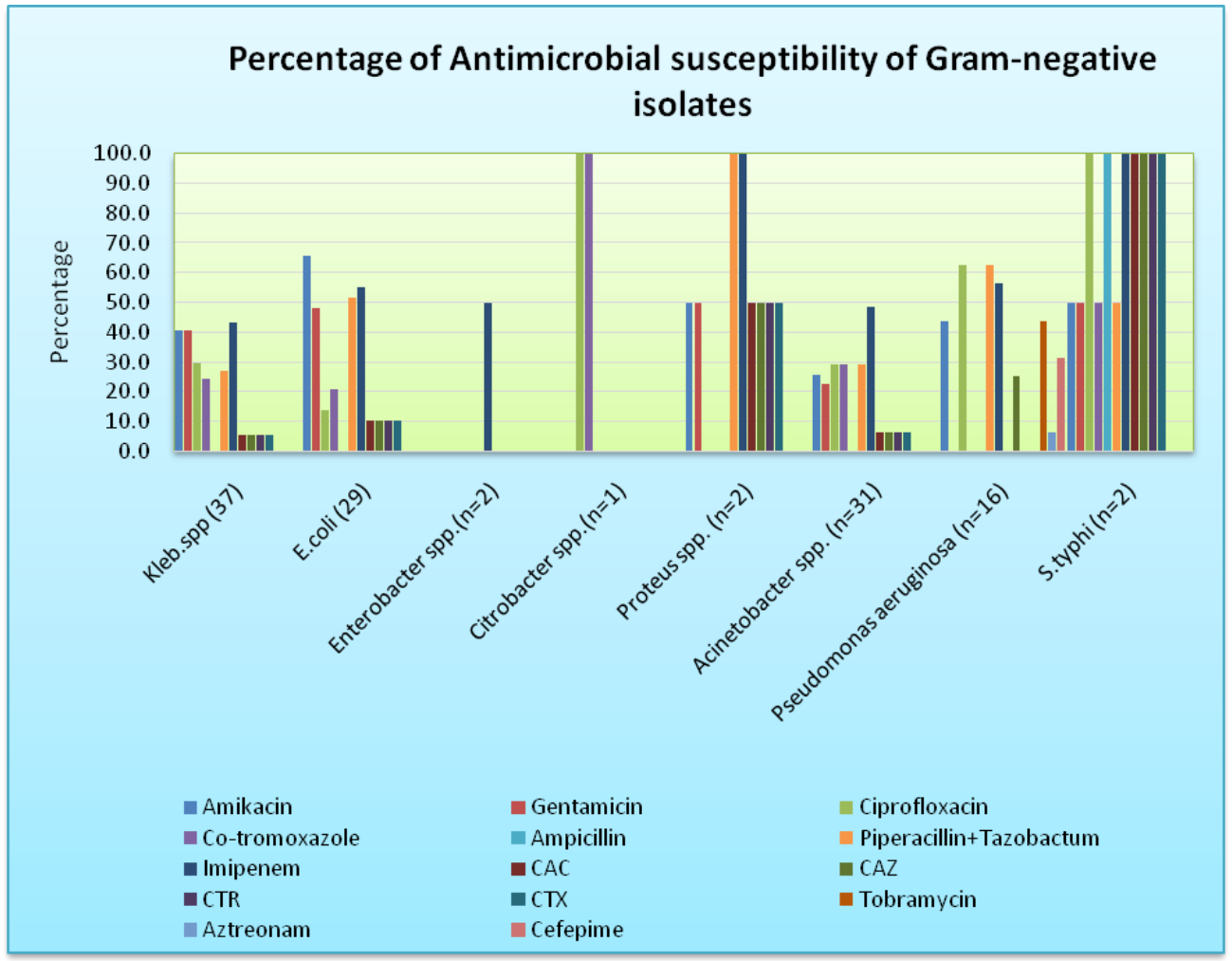

Fig.5 Percentage of Antimicrobial resistance in Gram-negative isolates $(p<.01)$.

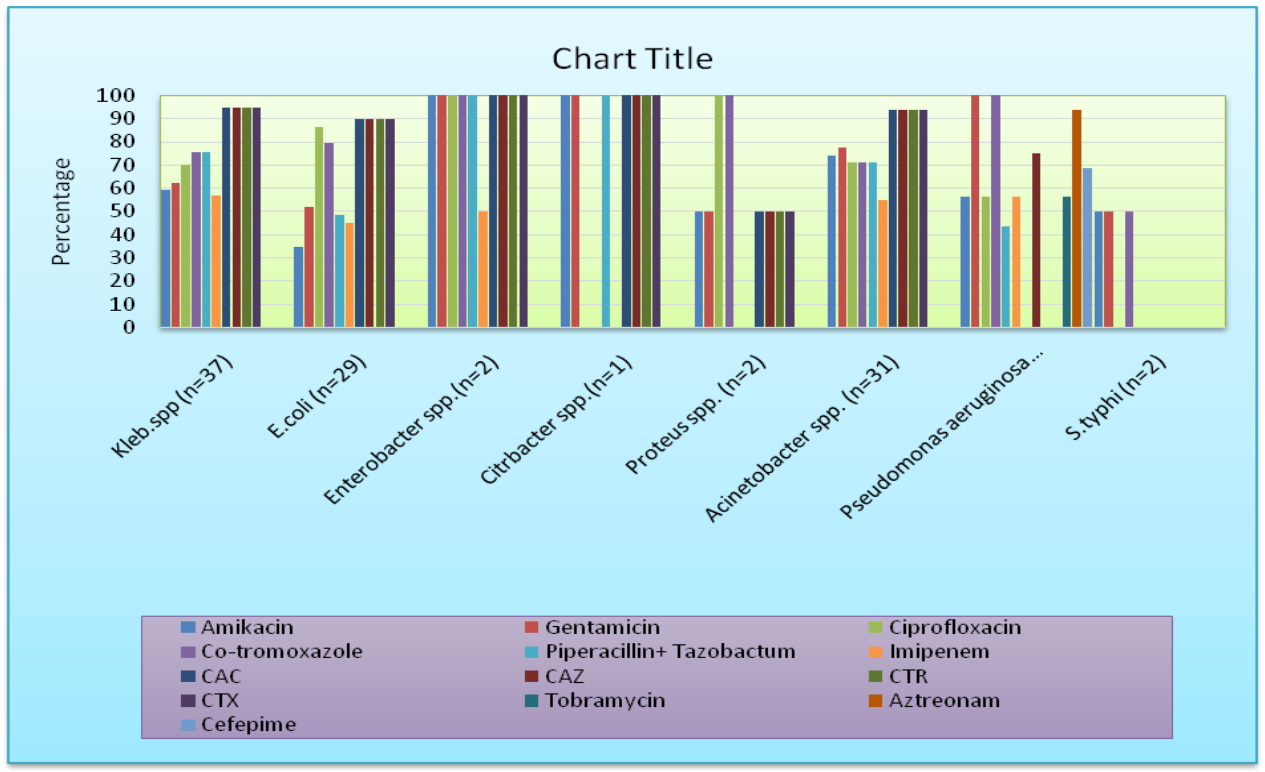


Of 31 Acinetobacter spp., 29 ((93.55\%) were resistant to Extended spectrum $B$ - lactamases while $22(70.97 \%)$ and $17(54.84 \%)$ were resistant to Piperacillin+Tazobactum and Imipenem respectively. $(\mathrm{p}<.01)$.

Among E.coli, 26/29 (10.34\%) \%) were resistant to Extended spectrum $\beta$ - lactamases while 45 to $48 \%$ (13 to 14/29) E.coli were resistant to Piperacillin + Tazobactum and Imipenem.

S.typhi was isolated from 2 patients which showed almost sensitivity to all antimicrobials $(\mathrm{p}<.01)$.

Pseudomonas aeruginosa showed (50-100\%) resistance towards Gentamicin, Cotrimoxazole, Aztreonam, Ceftazidime, Cefepime, Ciprofloxacin,Imipenem, Amikacin, Piperacillin - Tazobactum $(\mathrm{p}<.01)$.

With underlying diseases and the risk factors like age, decreasing immunity, instrumentation, Patients admitted in the intensive care units or critical care units, are always at a higher risk of developing healthcare- associated infections, which result in high morbidity and mortality, ICU stay, cost among these patients. With over \& indiscriminate use of antibiotics in ICU settings, pathogens isolated are emerging as multi-drug resistant under continues antibiotic pressure.

In view of this, the present study was done to know the most prevalent pathogen isolated along with their antimicrobial susceptibility patterns from adult patients with blood stream infections admitted in medical intensive care units.

The patients in this study were in the age group of 20 to above 60 years with Male to Female ratio was approximately 2: 1 .
Similar ratio was also observed in the earlier study ${ }^{21}$.With maximum bloodstream infections were observed in above 60 years of age group. This may be because of sepsis which is common in aging population with underlying disease, declining immunity make them prone to new infections. ${ }^{(22,23]}$

The epidemiology of microbial pathogens causing BSI's dramatically changed over years, with a concomitant increase in antimicrobial resistance.

A nationwide surveillance study conducted in 49 hospitals in USA showed a large prevalence of Gram-positive bacteria causing BSI's compared with Gram-negative organisms. However, a trend towards an increasing incidence of Gram-negative organisms causing BSI's has been observed more recently ${ }^{(24)}$.

The present study showed that there was more Gram - negative isolates (71.86\%) with predominance of Klebsiella pneumoniae (22.15\%) followed by Acinetobacter spp. (18.56\%), E.coli (17.36\%) and Pseudomonas aerugenosa $(9.58 \%)$ than the Gram - positive isolates (18.56\%) and Candida spp. (9.58\%). Similar observations were also stated by earlier studies. ${ }^{22,}{ }^{25},{ }^{26]}$ The emergence of MDR often is dedicated to excessive use of broad-spectrum antimicrobial agents, since more than $60 \%$ of all ICU patients receive antimicrobials during their stay in critical care unit ${ }^{(25)}$

In the present study, ESBL production was observed in 94 (78.33\%) Gram negative isolates. The most common ESBL - producers were Klebsiella pnuemonaie (35/37; 94.59\%) followed by Acinetobacter spp. (29/31; $93.54 \%)$ and E.coli (26/29; 89.65\%). Similar observation of maximum ESBL production in Klebsiella pneumonia and Acinetobacter spp. were also shown by previous studies ${ }^{(22,25)}$. 
ESBL-producing organisms have been described in USA since the 1980's and have been associated strongly with nosocomial infections.

Carbapenams antimicrobials are considered the first-line therapy for ESBL infections, but resistance to this antimicrobial class is becoming widespread. Since the first case of CRE occurred in North Carolina in $1996^{(27)}$.

In this study, Carbapenem - resistant phenotype was found in 61/120 (50.83\%) of Gram - negative isolates. It was most commonly found in Klebsiella pneumoniae and Acinetobacter baumannii isolates. 21/37 $(56.76 \%)$ were Klebsiella pneumoniae and 17/31 (54.84\%) were acinetobacter spp. similar observations were also found in the earlier studies ${ }^{(22,25,28)}$.

Whereas, Gram - negative isolates showed a variable susceptibility to Aminoglycosides, Piperacillin - tazobactum and Ciprefloxacin antibiotics. S.typhi was isolated from 2 patients which showed almost sensitivity to all antimicrobials. Pseudomonas aerugenosa showed (50-100\%) resistance towards Gentamicin, Co-trimoxazole,Aztreonam, Ceftazidime, Cefepime, Amikacin, Ciprofloxacin,Imipenem, Tobramycin.

Of 31 (18.56\%) Gram - positive islates, maximum isolation was of Enterococcus spp. $14(8.38 \%)$ and Staphylococcus aureus $11(6.59 \%)$ and CONS $4(2.40 \%)$. Whereas, the studies by Valles et al., (29) reported maximum isolation of CONS (20-30\%) causing BSI in ICU patients and Manmeet aur et al., ${ }^{(28)}$ reported $39.5 \%$ of CONS isolation.

Although, the CONS is also a very preventable cause of infection and these isolates are often skin colonizers and appear in blood cultures as common contaminants at the time of sample collection ${ }^{(22)}$ but is now a well described pathogen associated with the use of central venous lines, prematurity in neonates (28). In this study almost all strains of Enterococcusspp,CONS \&S.aureus showed $100 \%$ resistance to Penicillin. Methicillin resistance among S.aures isolates was $(54.55 \%)$ which was compararble to the earlier studies by Amit Bhatia et al., ${ }^{(22)}$ who reported $67 \%$ MRSA\& a rate of $52.9 \%$ described in the National Nosocomial Infections Surveillance (NNIS) data summary for the period $1992-2004^{(30)}$. Whereas, $75 \%$ Coagulase negative Staphylococcalspp. were Methicillin resistant. All gram-positive isolates showed $100 \%$ sensitivity towards Vancomycin and Linezolid.

The present study brings to light that the prior knowledge of the most prevalent multi - drug resistant pathogens causing blood stream infections in ICU and their antibiotic sensitivity patterns can be of help to the clinicians in choosing appropriate antimicrobial therapy thus reducing morbidity and mortality among admitted patients in ICU. With rise in the problem of emergence of multidrug - resistance in isolates, there should be continuous surveillance of data of clinical isolates with their sensitivity pattern along with the implementation of strict antimicrobial usage policies in health care setting. Thus In the absence of new antimicrobials, prevention of infections with optimal adherence to infection control measures, and a good antibiotic policy for the hospital through promotion of antimicrobial stewardship programmes is the need of the hour to stop or reduce drug resistance.

\section{References}

Claudio.Viscoli,"BloodstreamInfections: The Peak Of The Iceberg," Virulence,2016,Vol.7, No. 3, Page No. 248-251.

Matteo Bassetti, Elda Righi and Alessia Carnelutti. 'Bloodstream Infections in 
the Intensive care Units', Virulence, 2016, Vol.7, No.3, Pages: 267-279.

Barnett AG, Page K, Campbell M, Martin E, rashleigh-Rolls $\mathrm{R}$, Halton $\mathrm{K}$, Paterson DZ, Hall L, Jimmieson N, White $\mathrm{K}$, et al., " The Increased risk of death and extra lengths of hospital and ICU stay from hospital-acquired bloodstream infections: A case - control study'. BMJ Open 2013; 3: e003587; PMID: 24176795.

Bhatta DR, Gaur Abhishek, HS Supram. "' Bacteriological profile of bloodstream infections among febrile patients attending a tertiary care centre of Western Nepal ', Asian Journal of Medical Science, 2013, Vol-4, pages: 92-98.

Malacarne P, Bocealatle D, Acquarole A, Agostini F, Anghileri A, Giardino M, et al., " Epidemiology of Nosocomial Infection in 125 Italian Intensive Care Units',Minerva Anestesiol, 2010, 76 ; pages:13-23.

NeleBrusselaers, Dirk Vogelaers and Stijn Blot. 'The rising problem of antimicrobial resistance in the intensive care units', Ann Intensive Care, 2011, 1:47.PMC:3231873.

Marwick C, Davey P. Care bundles: the holy grail of infectious risk management in hospital? Curr Opin Infect Dis. 2009; 22:364-369.

Hanberger H, Garcia-Rodriguez JA, Gobernado M, Goossens H, Nilsson LE, Struelens MJ. Antibiotic susceptibility among aerobic gram-negative bacilli in intensive care units in 5 European countries. French and Portuguese ICU Study Groups. JAMA. 1999; 281:67-71. doi: 10.1001/jama.281.1.67.

Vincent JL, Bihari DJ, Suter PM, Bruining HA, White J, Nicolas-Chanoin MH, Wolff M, Spencer RC, Hemmer M. The prevalence of nosocomial infection in intensive care units in Europe. Results of the European Prevalence of Infection in Intensive Care (EPIC) Study. EPIC
International

Advisory

Committee. JAMA. 1995; 274:639-644.

Vandijck DM, Depaemelaere M, Labeau SO, Depuydt PO, Annemans L, Buyle FM, Oeyen S, Colpaert KE, Peleman RP, Blot SI, Decruyenaere JM. Daily cost of antimicrobial therapy in patients with Intensive Care Unit-acquired, laboratory-confirmed bloodstream infection. Int $\mathrm{J} \quad$ Antimicrob Agents. 2008; 31:161-165

Blot S. Limiting the attributable mortality of nosocomial infection and multidrug resistance in intensive care units. Clin Microbiol Infect. 2008; 14:5-13.

Blot S, Depuydt P, Vandewoude K, De Bacquer D. Measuring the impact of multidrug resistance in nosocomial infection. Curr Opin Infect Dis. 2007; 20:391-396

ZaveriJitendra R, Patel Shirishkumar M, Nayak Sunil N, Desai Kanan, Patel Parul.' A Study on Bacteriological Profile and Drug Sensitivity And Resistance Pattern Of Isolates Of The Patients Admitted In Intesive Care UnitsOf A Tertiary Care Hospital In Ahmadabad.' National Journal Of Medical Research.July September 2012, Vol: 2, Issue: 3, Page: 330-334.

Manjula M, Priya D, Varsha G. " Antimicrobial Susceptibility Pattern Of Blood Isolates From A Teaching Hospital In North India" Japan J Infect Diseases., 2005, Vol: 58, Pages: 174-176.

Rina K, Nadeem SR, Kee PN, Parasakhti N, "Etiology Of Blood Culture Isolates Among Patients In A Multidisciplinary Teaching Hospital In Kaula Lumpur", J Microbiol Immunol Infect, 2007 ; Vol: 40 ; Pages : 432-435.

Boucher HW, Talbot GH, Bradley JS, Edwards JE, Gilbert D, Rice LB, Scheld M, Spellberg B, Bartlett J. Bad bugs, no drugs: no ESKAPE! An update from the Infectious Diseases Society of America. Clin Infect Dis. 2009; 48:1-12

Jones RN. Resistance patterns among nosocomial pathogens: trends over the 
past few years. Chest. 2001; 119:397S$404 \mathrm{~S}$

Mackie and Macartney Mackie and McCartney, Practicle Medical Microbiology.

Baily and Scott Bailey andSott's Diagnostic Microbiology.CLSI guidelines

Preeti Raheja, Antarikshdeep, Uma Chaudhary. Microbiological Profile Of Hospital Acquired Blood - Stream Infections In Seriously Ill Medical Patients Admitted In Tertiary Care Hospital. International Journal of Research in Medical Sciences, May 2016; 4 (5): 1636 - 1640.

Amit Bhatia, Juhi Karla, Saurabh Kohli, Barnali Kalkati, Reshma Kaushik. Antibiotic resistance pattern in intensive care unit of a tertiary care teaching hospital.International Journal Of basic And Clinical Pharmacology. May 2018; Vol 7 ; Issue 5; Pages : $906-11$.

Seth KV, Patel TK, Malek SS, Tripathi CB. Antibiotic sensitivity pattern of bacterial isolates from the intensive care unit of tertiary care hospital in India.Trop J Pharm Res.2012; 11(6): 991-9.

Munoz P, Cruz AF, Rodriguez-Creixems M, Bouza E. Gram-negative bloodstream infections. Int $\mathrm{J}$ Antimicrob Agents. 2008;32(Suppl 1):S10-14

Jose Orsinia, d, Carlo Mainardia, Eliza Muzyloa, Niraj Karkia, Nina Cohenb, George Sakoulas. Microbiological Profile of Organisms Causing Bloodstream
Infection in Critically Ill Patients. J Clin Med Res • 2012;4(6):371-377

Wattel C, Raveendran R, Goel N, Oberoi JK,Rao BK. Ecology of blood - stream infection and antibiotic resistance in intensive care unit at a tertiary care hospital in North India.Brazilian Journal Of Infectious Diseases. 2014; 18(3) : 245-51.

Yigit H, Queenan AM, Anderson GJ, Domenech-Sanchez A, Biddle JW, Steward CD, Alberti S, et al., Novel carbapenem-hydrolyzing betalactamase, KPC-1, from a carbapenemresistant strain of Klebsiella pneumoniae. Antimicrob Agents Chemother. 2001; 45(4):1151-1161

Manmeet KAur Gill, Sarabjeet Sharma. Bacteriological profile and antimicrobial resistance pattern in blood - stream infection in critical care units of a tertiary care hospital in North India.Indian Journal Of Microbiological Research. 2016; 3(3): 270-274

Valles J, Ferrer R. Blood stream infections in the ICU. Infectious Dis Clin North Am. 2009; 23(3):557-69.

National Nosocomial Infections Surveillance (NNIS) System Report, data summary from January 1992 through June 2004 issued October 2004. J Infect Control. 2004; 32(8):470-485.

\section{How to cite this article:}

Jyoti P. Sonawane, Keertana S. Shetty, N. Kamath, NitinBharos and Abhay S. Chowdhary 2019. Bacteriological Profile and Antibiogram of isolates From Bloodstream Infections in Patients Admitted in ICU from a Tertiary care hospital, Nerul, Navi Mumbai, India. Int.J.Curr.Microbiol.App.Sci. 8(09): 1752-1723. doi: https://doi.org/10.20546/ijcmas.2019.809.198 